\title{
Enhanced cooling of the mantle caused by the launch of modern plate tectonics
}

He LIU $^{123}$, TIM JOHNSON ${ }^{4}$, QIAN CHEN ${ }^{123}$, YONGJUN LU ${ }^{6}$, WEI-DONG SUN ${ }^{123}$

${ }^{1}$ Center of Deep-Sea Research, Institute of Oceanology, Chinese Academy of Sciences, 7 Nanhai Road, Qingdao 266071, China

${ }^{2}$ Laboratory for Marine Mineral Resources, Qingdao National Laboratory for Marine Science and Technology, Qingdao 266237, China

${ }^{3}$ Center for Ocean Mega-Science, Chinese Academy of Sciences, 7 Nanhai Road, Qingdao 266071, China

${ }^{4}$ Geological Survey of Western Australia, Department of Mines, Industry Regulation and Safety, 100 Plain Street, East Perth, WA 6004, Australia

${ }^{5}$ School of Earth and Planetary Sciences, The Institute for Geoscience Research (TIGeR), Space Science and Technology Centre, Curtin University, Perth, Western Australia 6845, Australia

${ }^{6}$ Geological Survey of Western Australia, Department of Mines, Industry Regulation and Safety, 100 Plain Street, East Perth, WA 6004, Australia

Earth's mantle has experienced a secular cooling process over geological history as suggested by most previous studies. However, the cooling model of the mantle is only roughly constrained due to the lack of sufficient samples formed by the melting of the hot ambient mantle. Here we apply a statistical analysis to the alkalinity of global-scale basalts formed in the intracontinental settings and produce a more detailed thermal evolution trend of the mantle based on the previous model. Our result reveals a remarkable mantle cooling event around the Cryogenian, coinciding with the Snowball Earth glaciation and the onset of modern plate tectonics. Before the Cryogenian, the mantle potential temperature $\left(T_{\mathrm{P}}\right)$ was almost constant for 1 billion years, consistent with the previously defined Earth's middle age. The Snowball Earth event might have kick-started the onset of modern plate tectonics. We conclude that the establishment of a globally linked network of plate boundaries and the transiently accelerated subduction at the beginning of modern plate tectonics could significantly enhance the cooling of the mantle by subducting a larger volume of cold oceanic slabs into the mantle. In contrast, the Earth's middle age represents a period of minimum subduction flux during the postArchean time, and therefore corresponds to a relatively stable thermal state of the mantle. 